\title{
Myeloablative Chemotherapy
}

National Cancer Institute

\section{Source}

National Cancer Institute. Myeloablative Chemotherapy. NCI Thesaurus. Code C16231.

The administration of high-dose chemotherapy, with or without total body irradiation, to eradicate the underlying disease and/or ablate the immune system of the patient. 